\title{
Development of Customers Satisfaction Model in Banking Sector Using Fuzzy Cognitive Map
}

\author{
Alo Oluwaseun $^{1 *}$ Fenwa Deborah ${ }^{2 *}$ Adedeji Oluyinka ${ }^{3 *}$ \\ 1. Information System Department, Ladoke Akintola University of Technology, P.O box 4000, Ogbomoso \\ Oyo state, Nigeria. \\ 2. Cyber Security Department, Ladoke Akintola University of Technology, P.O box 4000, Ogbomoso Oyo \\ state, Nigeria \\ 3. Information System Department, Ladoke Akintola University of Technology, P.O box 4000, Ogbomoso \\ Oyo state, Nigeria \\ *E-mail of the corresponding authors: ooalo@lautech.edu.ng, odfenwa@lautech.edu.ng, and \\ otadedeji@lautech.edu.ng
}

\begin{abstract}
Customer satisfaction is one of the key factors in modern marketing and customer's behavior analysis. Banking industry is one of the numerous services in which the customer satisfaction has had an ever increasing importance in the corresponding research areas. The problem here is the complexity of dealing with customer satisfaction due to super abundant factors engaged in it. In this paper the applications of Fuzzy Cognitive Maps (FCM's), as a decision making tool, in banking industry, a very vital part of a country's economy, has been discussed.

The paper focuses on the development of customers' satisfaction model in banking sector using fuzzy cognitive map. A questionnaire assessing customer's opinions to give a clear perception of factors affecting customer satisfaction in banks was designed based on Complaint handling, Service quality, Service feature, Competiveness and Convenience, which are the five major factors considered. The questionnaire was administered to bank managers, other bank staff and the customers within selected banks (First bank, Polaris bank and Wema bank) in Ogbomosho environ, Oyo state South-West Nigeria. The opinions from the administered questionnaires were quantitatively analysed using descriptive statistic in Statistical Package of Social Sciences. The analysis on five factors considered which are: Complaint handling, Service quality, Service feature, Competiveness and Convenience and defining the relationship between the factors were then used to develop the FCM model with the use of mental modeler software.

The nodes of the FCM model represent the main factors affecting customer satisfaction in banking sector and running of 'what if' scenario to determine how the model might react under possible change. The simulated results show that Service quality and Complain handling has a degree of effect on Customer satisfaction while other factors has no effect on customer satisfaction which could be positive and negative impact on customer satisfaction in banking sector. This implies that Service quality and Complain handling are important factors in predicting the customer satisfaction in banking sector.
\end{abstract}

Keywords: Customer satisfaction, Fuzzy Cognitive Map (FCM), Model, Banks and Decision.

DOI: $10.7176 / J I E A / 10-4-06$

Publication date:September $30^{\text {th }} 2020$

\section{Introduction}

Customer satisfaction is an important issue for marketing managers, particularly those in services industries in general, if the customers are satisfied with a provided goods or a particular service, the probability that they use the service again increase but the problem here is the complexity of dealing with customer satisfaction. With information societies flourishing, as one of the characteristics of the modern millennium, social interactions are becoming more complex and vague. It is apparent that decisions which, until a few decades ago, could have been made very easily, now lead to very complicated equations and formulas. Many of academicians and scholars around the world have emphasized the importance of clients. Top performing financial institutions, customers are the main reason for their existence in marketplace, and they are very dependent. The customers are not only the reference of issue. Therefore, the Banks should never wish that customers "should be drive away" because their future and protection would be at risk. These forms the main reason banks in the current times are giving too much commitment to customer gratification, retention, and faithfulness (Bloemer,1998).

Fuzzy Cognitive Map (FCM) models the behavior of a system in terms of interacting concept; each concept represents an entity, a state, a variable, or a characteristic of the system (Kosko 1986). FCM models are easily 
understandable as they are similar to the human reasoning procedure, but they require experts' Knowledge and contribution during the designing procedure. FCMs constitute a modelling and simulation tool to analyze decision making process for complex systems. The result of modelling any process depends on the available data, description, information, knowledge and the suggested modelling approach. The fact that FCMs are based on knowledge of experts, which is affected by their experience and background, makes FCMs subjective and potentially vulnerable to possible errors and conflicts. Apart from that, not every possible condition may have been included during the construction of the model, which makes it insufficient. Thus, the results depend on the quality of data that are used to create the model. FCM modelling creates an abstract representation of a real world system. The modelling and simulation process is simplified, while many assumptions about the system are made, the system's essential relationships are retained and unnecessary detail is omitted.

A bank may be defined as an institution that accepts deposits, makes loans, pays checks, and provides financial services. A bank is a financial intermediary for the safeguarding, transferring, exchanging, or lending of money. A primary role of banks is connecting those with funds, such as investors and depositors, to those seeking funds, such as individuals or businesses needing loans. A bank is the connection between customers that have capital deficits and customers with capital surpluses. The Central Bank of Nigeria $(\mathrm{CBN})$ is the apex regulatory authority of the financial system in Nigeria. It was established by the Central Bank of Nigeria Act of 1958 and commenced operations on 1st July 1959. Among its primary functions, the Bank promotes monetary stability and a sound financial system, and acts as banker and financial adviser to the Federal Government, as well as banker of last resort to the banks. The Bank also encourages the growth and development of financial institutions. Enabling laws made in 1991 gave the Bank more flexibility in regulating and overseeing the banking sector and licensing finance companies, which hitherto operated outside any regulatory framework (Ennew and Binks, 1996).

\section{Literature Review}

\subsection{Factor that Affect Customer Satisfaction}

\subsubsection{Service quality}

The banking sector in Nigeria like many other sectors has been experiencing a rapidly changing market, new and modern technologies, economic uncertainties, changing and more demanding customer services and above all fierce competition, that has presented an unpredictable set of challenges for them. In order to face this constant evolution of new challenges, the commercial banks have to reinvent their understanding of their clients and reexamine the value and service quality to assure that they make far-reaching implications in terms of service quality and customer satisfaction. In order to be successful in the market, it is not only sufficient for commercial banks to attract new customers but also concentrate on retaining existing customers implementing effective policies of customer satisfaction. Customer satisfaction can be considered as the essence of success in today's highly competitive world of business. Customer satisfaction increases the existing customer loyalty, repurchase process, awareness of the people about the firm, decrease the price flexibility, the cost of gaining new customers and prevent the customers from being affected by competitive enterprise (Anderson, 1996).

\subsubsection{Service feature}

Nowadays banking has changed because banking services are no more based on brick and mortar structure. Due to growth of technology, increasing customer base, the evolution of alternate banking channels, has changed the way of banking services, so hence the customer satisfaction. Banking is a customer-oriented service industry and customer satisfaction has become the most important aspect of any banking business due to immense competition. Banks are more determined to retain their existing customers by providing quality services leading to customer satisfaction. The concepts and determinants of customer satisfaction have changed significantly as the transition has taken place from traditional to modern banking. This could be witnessed by exploring the literature regarding customer satisfaction in the banking industry. This paper is based on an extensive literature review and attempts to investigate how the concepts and determinants of customer satisfaction have changed significantly during the transition from traditional to modern banking. Excellent customer service and the quality of customer experience is the factor for customers to choose to stay with a bank. Customer Satisfaction Index (CSI) is measured to determine customer satisfaction in banking industry by weighted score that assigns importance ratings of the objectives of service verticals and associated measures. On which survey feedbacks provided by customers on the service delivery of the banks. The service feature component of this research work is Complete range of service (Gil, Berenguer and Cervera, 2007). 


\subsubsection{Convenience}

Customers want merchandise that is well organized, attractively displayed and easy to find. That's how today's customers define convenience, and the easier you can make the shopping, the more money you will be lugging to the bank. The banking industry has been rapidly developing the use of Internet banking as an efficient and viable tool to create customer value. It is one of the popular services offered by traditional banks to provide speedier, convenience and reliable services to online users. With the rapid development of computer technology as a commercial tool Internet banking can be used to attract more customers to perform banking transactions in related banks (Athanassopoulos.,2000).

\subsubsection{Complaint handling}

In certain circumstances, customers become almost inevitably unhappy due to various problems or difficulties that are not always under the direct control of the company. Encouraging clients to express their discontent is the first step recommended to managers in their effort to systematically learn about customer negative experiences, restore satisfaction and strengthen business relationships (Feit, 2002). Complaints should be considered an indicator of organizational performance assessment, signaling some problems or failures in internal processes that need quick recovery in order to avoid the migration of profitable customers. Furthermore, organizations must learn that the consequences of losing clients are both profit decrease and negative word of mouth (Feit, 2002).

\subsubsection{Competiveness}

The perfect competition model of banking industry is not realistic due to the presence of considerable barriers to entry, switching costs and information asymmetries. Therefore, an oligopolistic model with a finite number of banks is employed in which the deposit and loan rates depend on the number of banks and the intermediation margin is lowered by an increase in the number of banks in the industry. Therefore, when competition in the banking industry intensifies profits realised from the difference between deposit and loan rates is reduced banking competition and macroeconomic performance (Dataiku, 2013).

\subsection{Fuzzy Cognitive Map}

Fuzzy Cognitive Maps (FCM), as introduced by Kosko, are a combination of Neutral Networks and Fuzzy Logic that allow us to predict the change of the concepts represented in Causal Maps. They are fuzzy directed graphs with feedback, consisting of various nodes (representing the change in concepts like inflation or Police Vigilance) and directed arcs that connect and represent the causal relation between those nodes FCMs use fuzzy logic; hence they can incorporate vagueness and qualitative knowledge and also feedback processes. They can be used to simulate the changes of a system and can also address 'what if' questions (Kosko, 1992). Regarding modelling, FCMs can combine aspects of qualitative methods with the advantages of quantitative methods. FCMs allow dynamically simulating and testing the influence of various scenarios and have been used to reach a decision or to evaluate a procedure or examine management scenarios on system components. Modelling with FCMs is a simple and transparent way for representing and useful to describe any system in many fields such as engineering, medicine, Business and so on. Besides, FCM models can be highly accurate. However, the more complex a system is, the more accurate it is, but complexity decrease the comprehensibility of the system. The basic FCM model has been used in many applications in various fields and for different purpose. The simulation gave generally satisfactory results. However, each model has its own drawbacks with respect. To the field that is used. For example, in business and management, FCMs have been used to model and simulate the information system strategic planning process (SISP) (Vinox and Bosquet 2010.).

FCMs are able to model and simulate systems in a wide variety of application areas, because of their capability to handle complexity with much and/or even in complete or conflicting information. FCMs have been used in many fields, solving a variety of different problems, including social and political sciences, medicine, business and management, engineering, environment and agriculture, information system and technology, education. Each application has various concepts corresponding to the problem which is under investigation. The large number of concepts makes the system more accurate and completed. However, the less complex a system is the more comprehensible and readable it is. The need for better handling the increased complexity of some applications led to enhance FCMs with learning methods, use of levels and/or separation of the initial complex problem into multiple FCMs and use a supervisor to control the system or use other methods synergistically. Fuzzy cognitive mapping is a tool for formalizing understandings of conceptual and causal relationships. By combining conceptual mapping tools with fuzzy logic and other techniques originally develop for neutral networks, FCMs allow for the representation and formalization of soft knowledge domains e.g., politics, education (Kosko, 1992) . 


\subsection{Mental Modeler (FC-Map)}

Mental Modeler is a decision-support software intended to help individuals and communities understand the impacts associated with environmental change and develop mitigation strategies to reduce unwanted outcome by capturing, communicating and representing knowledge. Through a multi-step process based in fuzzy-logic Cognitive Mapping semi-quantitative models of environmental issues which:

1. Define the important components relevant to a community,

2. Define the strength of relationships between these components

3. Run "what if" scenarios on these models to determine how the system might react under a range of possible condition.

Mental Modeler is comprised of three main user interfaces:

a) The concept mapping interface that provides a space for model building and parameterizes model construction in the format required for FCM analysis;

b) The matrix interface that allow the structural properties of the cognitive map (i.e. a representation of a mental model or group knowledge) to become clear by examining pair wise relationships; and

c) The scenario interface which allows stakeholders to run and compare change within the system under different potential scenarios and revisit and revise their models in the concept mapping interface in light of this new information (Steven, 2013) .

\subsection{Related works on Fuzzy Cognitive}

Ath. Markinos (2007) introduced FCMs to model a decision support system for precision Agriculture (P.A). The FCM model develops consists of nodes which describe soil properties and cotton yield and of the weighted relationships between these nodes. The nodes of the FCM model represent the main factors influencing cotton crop production i.e. essential soil properties such as texture, $\mathrm{PH}, \mathrm{OM}, \mathrm{K}$, and $\mathrm{P}$. The proposed FCM model address the problem of crop development and spatial variability of cotton yield, taking into consideration the spatial distribution of all the important factors affecting yield. In designing the FCM model for precision farming, one experienced cotton farmer and two experienced soil scientists played the role of experts and they designed the FCM model following the development methodology described in (Stylios and Groumpos 1998). The three experts stated that there are eleven main factors-concepts (which represent soil properties) that determine the cotton yield. The output concept $\mathrm{C} 12$ represent the first cotton yield picking measured with the yield monitor. The set of linguistic variables that every concept can take and corresponding membership functions for the four selected soil parameters (e.g. sand, clay, OM and shallow EC). Then, the experts were asked to describe the degree of influence from one concept to another using IF-THEN rules among factor concepts and yield.

Nyaki (2014) used fuzzy-logic cognitive mapping in Bush-meat management policies which are often developed outside the communities in which they are to be implemented. These policies are also routinely designed to be applied uniformly across communities with little regard for variation in social or ecological conditions. FCM was used to compare the assumptions driving externally generated bush-meat management policies with perceptions of bush-meat trade dynamics collected from local community members who admitted to being recently engaged in bush-meat trading (e.g., hunters, sellers, consumers). Data were collected during 9 workshops in 4 Tanzanian villages bordering Serengeti national park. Specifically, Nine (9) communities were evaluated to generate models for the presence of the central factors that comprise and drive the bush-meat trade and whether or not model included the same core concepts, relationships, and logical chains of reasoning on which fish-meat conservation policies are commonly based. Across local communities, there was agreement about the most central factors important to understanding the bush-meat trade (e.g., animal recruitment, low income, and scarcity of food crops) which matched the policy assumptions. However, the factor perceived to drive social-ecological bush-meat trade dynamics were more diverse and varied considerably across communities (e.g., presence or absence of collaborative law enforcement, increasing human population, market demand, and cultural preference). Sensitive conservation issues, such as the bush-meat trade that require cooperation between communities and outside conservation organization can benefit from participatory modelling approaches that make local-scale dynamics and conservation policy assumption explicit. Further, communities' and conservation organization' perceptions need to be aligned. This can improve success by allowing context appropriate policies to be developed, monitored, and appropriately adapted.

\section{Methodology}

3.1 Design of Questionnaire on the factors which affect the Performance of Customer Satisfaction in Banking 
Sector

The customer satisfaction in banking was been carried out by surveying and collecting the responses of experts in Banking sector. The processes involved in the study are as follow:

\subsubsection{Gathering and formulation of major Event}

This is the most important, and time consuming aspect of the process, it involves desk/ field research activities on literatures, Journals, and textbooks that talked about the customer satisfaction in banking sector. Wema banks, First bank, Polaris bank in Ogbomosho, Oyo state, South-West Nigeria were used as case study. In the collation of the questionnaire, the branch bank managers, other bank staff and the customers of the following banks were responsible for the extraction of information about factors responsible for customers' satisfaction in banks and also inherent survey was not left out to get related information which was useful in drawing out the major events. Therefore, major factors were filtered out from the numerous factors gathered from the literatures and survey conducted.

\subsubsection{Design of Questionnaire}

In this paper, the aim of the questionnaire was to carry out a survey that would capture critical data on factors affecting customer satisfaction in banking sector. Face-to-face interview with the respondents were used during the course of survey. A Likert rating scale is psychometric scale commonly used in questionnaires and is the most widely used scale in survey research. The expert respondent to the questionnaires using a likert rating scale ranges from 1 to 5 . The meaning of the likert scale follows this trend:
1. Strongly Agree
2. Agree
3. Normal
4. Disagree
5. Strongly Disagree

\subsubsection{Procedure for Data collection}

The first part of data collection involved the scientific and purpose sampling of respondents from Wema bank, Polaris bank, and First bank branches Ogbomosho, Oyo state Nigeria. A total of 100 copies of questionnaire were administered via face-to-face interview with the respondents. A total number of 96 (i.e. 96\%) of questionnaires were correctly filled, returned and used for this research work.

\subsubsection{Data Analysis}

The first step of the analysis is data coding. The data was coded into a format with numerical code using the Microsoft excel. The major events/factors under consideration were coded as bellows:

Event 1: Service Quality

Event 2: Convenience

Event 3: Service Feature

Event 4: Complain Handling

Event 5: Competiveness

\subsubsection{Implementation of fuzzy cognitive map using Mental Modeler}

In developing the FCM model, mental modeler was used, and this comprises of three main user interfaces as follows: The first interface is the concept mapping interface which provides a spare for model building and parameterizes model construction in the format required for FCM analysis which help in defining the important factors relevant to the customer satisfaction and weighting the strength of relationship between the factor of customer satisfaction in banking industry using a quantitative values between -1 (high negative) and +1 (high positive) values used and also in the matrix interface showing the alternative view to model that are represented by high positive $1(+++)$, medium positive $0.50(++)$ low positive $0.25(+)$ or high negative $-1(---)$, medium negative -0.50 (--) and low negative $-0.25(-)$.

Second interface is the matrix interface which provides alternative view to the model and the scenario tab for running "what if" scenarios on the models to determine how the factor might react under a range of possible conditions. By setting a value between $\mathrm{H}+$ (strong positive change in factors) and $\mathrm{H}$ - (strong negative change in factors). Relative change in the model is displaced as a bar graph to indicate how the factors react under a given simulation. 


\section{Result and Discussion}

\subsection{The Developed FCM model of Customer Satisfaction in Banking Sector}

The developed FCM model for the customer satisfaction in banking sector is shown in Figure 4.1. In modeling the fuzzy cognitive map, the knowledge and opinion of experts, the use of expert analysis and related journals on factor affecting customer satisfaction in banks were used to draw the fuzzy cognitive map model for the established factors and also defining the relationship between the factors and the effect that one factor have on each other which then forms the conceptual model developed in this work.

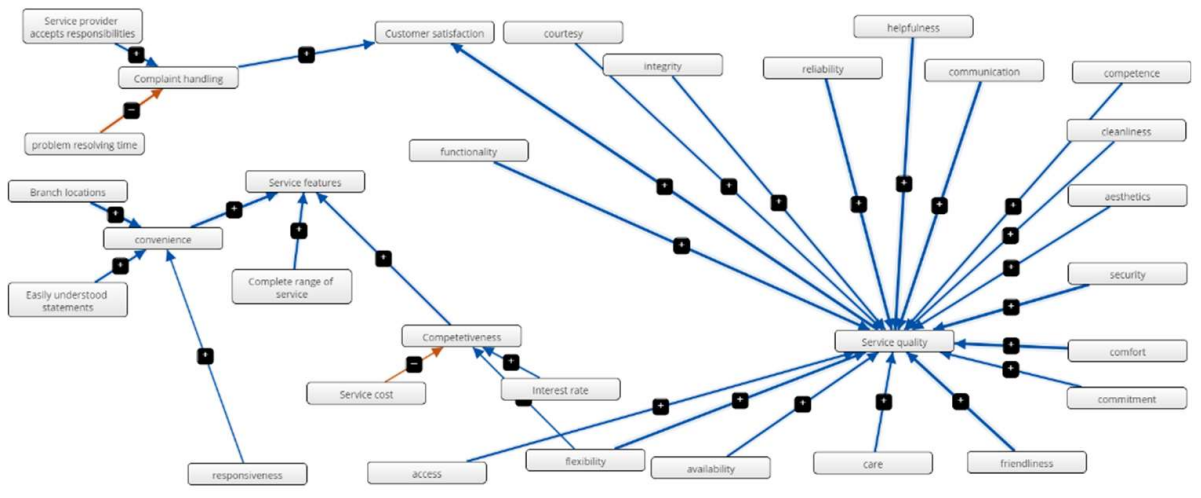

Figure 4.1: The developed FCM model for Customer Satisfaction in Banking sector

\subsection{Results on the simulation factors}

The simulation result shows that Service quality and Complain handling has a degree of effect on Customer satisfaction while other factors has no effect on customer satisfaction which could be positive and negative impact on customer satisfaction in banking sector. The relative change in the model is been shown as a bar graph to indicate how factors might react under a given simulation.

\subsubsection{Running a 'What if' scenario on Service quality}

The simulated scenario on Service quality showed that an increase in Service quality cause an increase in customer satisfaction with $0.04 \%$ respectively as shown in Figure 4.2 while a decrease in this factor caused a decrease in customer satisfaction with $-0.39 \%$ respectively as depicted in Figure 4.3 . This result showed that the impact of Service quality has brought positive and negative impact on customer satisfaction in two case scenarios.

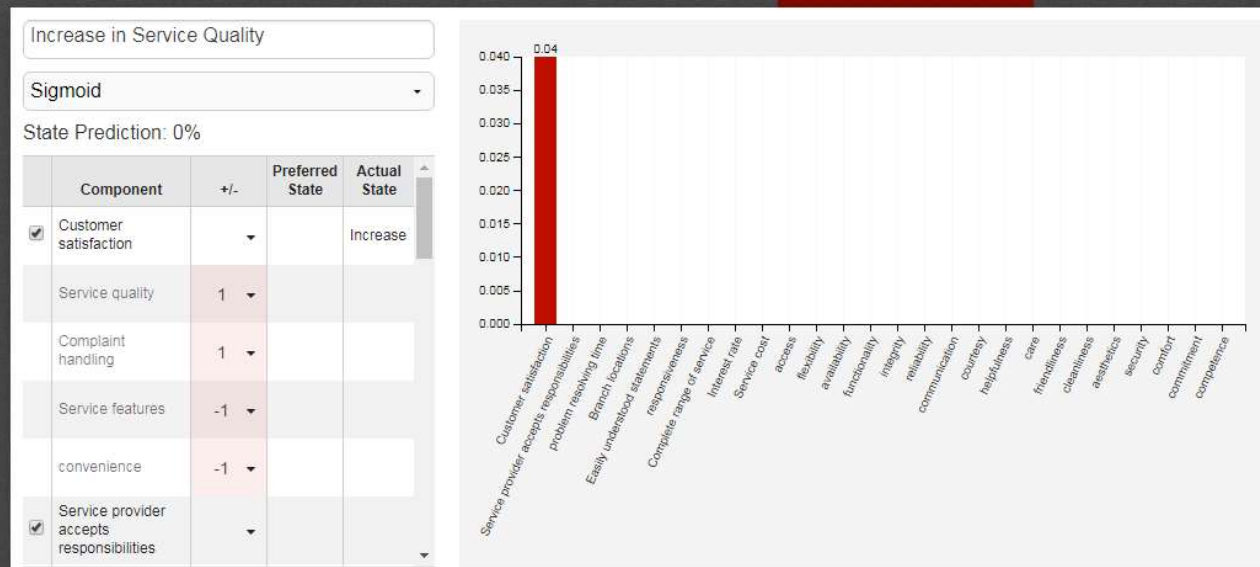

Figure 4.2: Predicting Increase in Service quality 


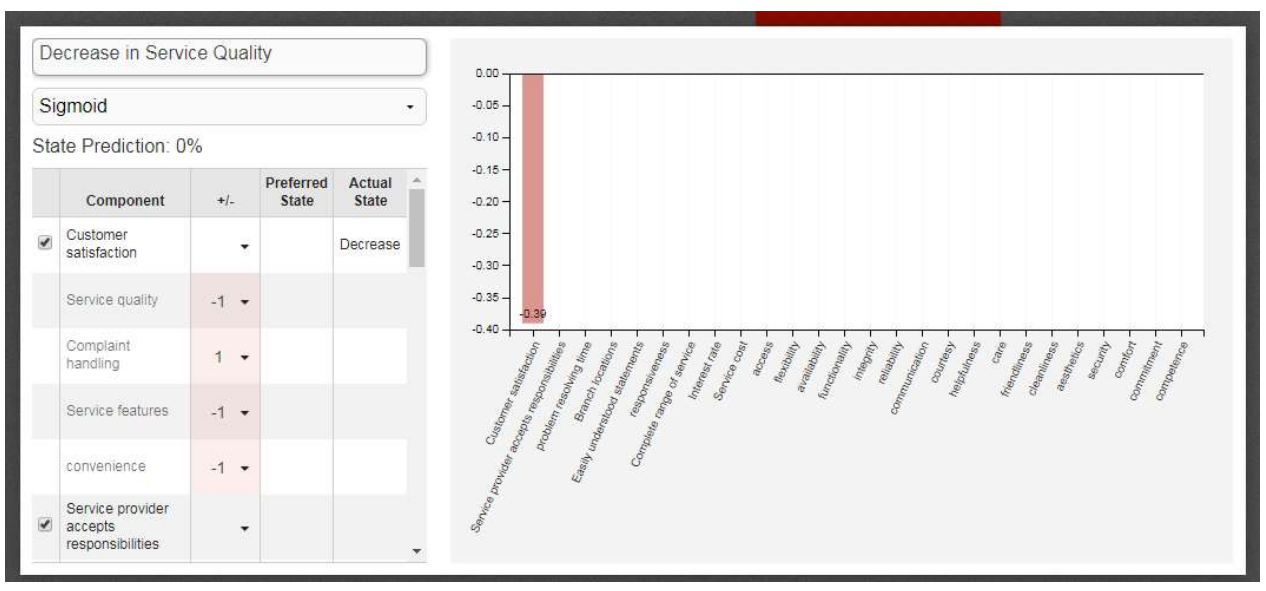

Figure 4.3: Predicting Decrease in Service quality

\subsubsection{Running a 'What if' scenario on Complaint Handling}

The simulated scenario on Complaint Handling showed that an increase in Complain handling cause an increase in customer satisfaction with $0.04 \%$ respectively as shown in Figure 4.4 while a decrease in this factor caused a decrease in customer satisfaction with $-0.18 \%$ respectively as depicted in Figure 4.5 . This result showed that the impact of Service quality has brought positive and negative impact on customer satisfaction in two case scenarios.

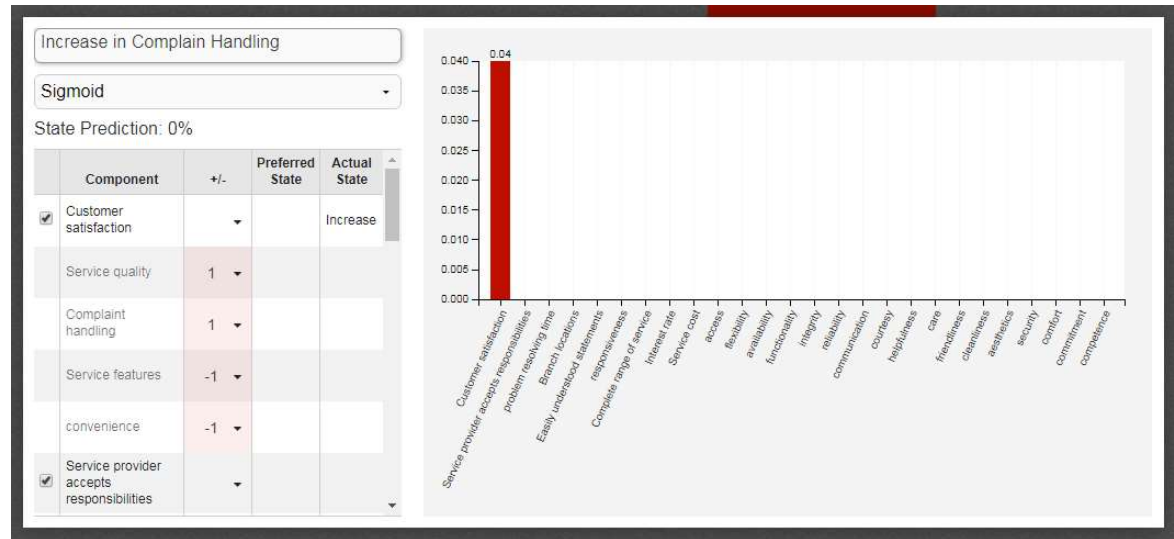

Figure 4.4: Predicting Increase in Complaint handling

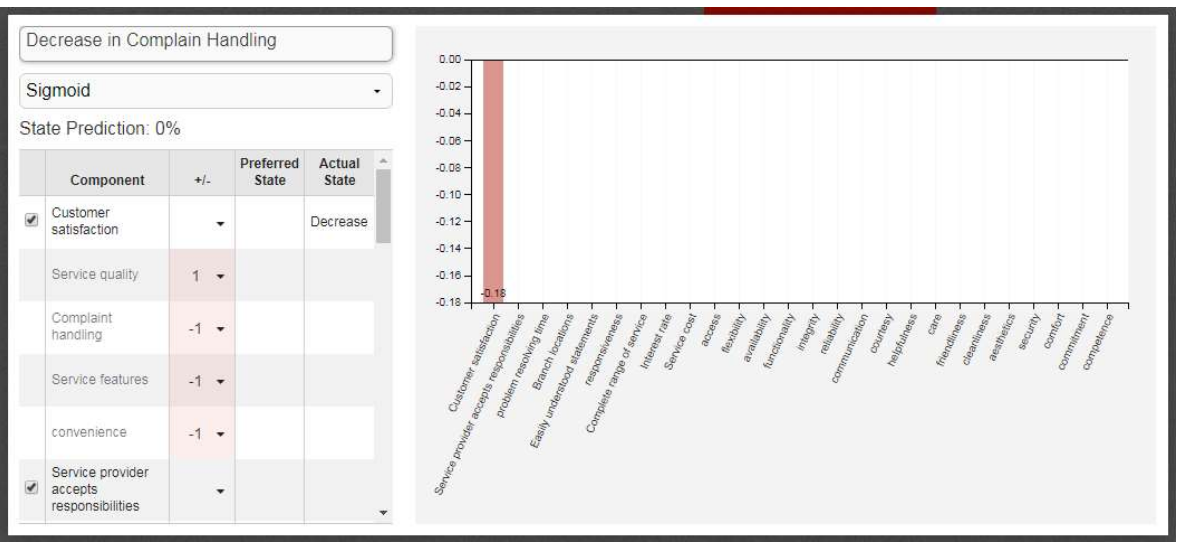

Figure 4.5: Predicting Decrease in Complaint handling 


\section{Conclusion}

The study determined the five major important factors which are responsible for the customer satisfaction in Banking Sector, The factor are: Service quality, Service Feature, Complaint Handling, Convenience, and Competiveness. Also, the Fuzzy Cognitive Map for the customer satisfaction in banking sector drawn by using the factors which were collected by enquiring the knowledge of expert and browsing the internet on factor affecting customer satisfaction in banking sector. The developed FCM model consists of nodes-factors (describing elements of the model) which are connected with weighted edges (representing the cause and effect of relationships among the factor) between the nodes. The nodes of the FCM model represent the main factors affecting customer satisfaction in banking sector and running of 'what if' scenario to determine how the model might react under of possible change. The simulated results show that Service quality and Complain handling has a degree of effect on Customer satisfaction while other factors has no effect on customer satisfaction which could be positive and negative impact on customer satisfaction in banking sector. This implies that Service quality and Complain handling are important factors in predicting the customer satisfaction in banking sector.

\section{References}

Anderson, E. W. (1996), “Customer Satisfaction and Price Tolerance,” Marketing Letters, 7 (3), 19-30

Anderson, E.W. and Sullivan, M. (1993), "The Antecedents and consequences of consumer satisfaction for firms" Marketing Science, Vol. 12, spring, pp. 125-143.

Anderson, E.W., Fornell, C. and Lehmann, D.R. (1994), “Customer Satisfaction, Market Share, and Profitability: Findings from Sweden,” Journal of Marketing, 58 (3), 53-66.

Ath. Markinos (2007): A decision support system for precision agricultural (PA).

Athanassopoulos A.D(2000)., Customer Satisfaction Cues to Support Market Segmentation and Explain Switching Behavior, Journal of Business Research, Volume 47, Issue 3, Pages 191-207.

Bloemer, J. (1998). Investigating derivers of bank loyalty: the complex relationship between image, service quality and satisfaction. International Journal of Bank Marketing, 16(7), 276-286.

Ciavolino,E., Dahlgaard, J.J. (2007), Customer Satisfaction Modelling and Analysis

Dataiku (2013) Finance Current Application and Trend as Predictor of customer financial institutions across several different channels.

Ennew, C. and Binks, M. (1996), Good and Bad customers: the benefits of participating in the banking relationship, International Journal of Bank Marketing Vol.14 No.2, pp.5- 13.

Feit,T.L.(2002),CustomerSatisfactionSurveyDevelopment(www2.uwstout.edu/content/lib/thesis/2002/2002feitt.p df) (Assessed on 21/02 2011).

Gil I., Berenguer G. and Cervera A(2007)., The roles of service encounters, service value, and job satisfaction in achieving customer satisfaction in business relationships, Industrial Marketing Management.

Brubaker, D. (1996). Fuzzy cognitive maps. EDN, 209. 60

Nyeki Angela, Stephen A. Gray, Christophera A. lepczyk, Jeffrey C, Skibin abd Dennis Rentsh (2014); local-scale Dynamics and local Drivers of Bush meat-Trade, Conservation Biology, Volume 00, No. 0, 1-12, DOI:10.1111/COBI.12316, PP 1-12.

Steven A. Gray (2013) Mental Modeler: A fuzzy-Logic Cognitive Mapping Modelling Tool for Adaptive Environment Management, IEEE, 1530-1605/12, DOI 10.1109/HICSS.2013.399, PP 965-9.

Steylios, C. D. and Grounmpous, P.P (1998) The Challenge of modelling Supervisory Sysem using Fuzzy Cognitive maps. Journal Intelligent Manufacturing, 9.

Taber, R. (1991) knowledge processing with Fuzzy Cognitive Maps. Expert Systems with Applications, 2,83-7.

Vinox, A and Bosquet, F. (2010). Modelling with stakeholders. Environment modelling \& $\quad$ Software 25,12681281.

Gray, S., Gagnon, A.,Gray, S., Mahony, C., Muir, D., Falaleeva, M.(2014). Are local coastal managers detecting the problem? Assessing stakeholder perception of climate vulnerability using Fuzzy Cognitive Mapping. Ocean and Coastal Management. 94:74-89.

Gray, S., Zanre, E., and Gray S.(2013). Fuzzy Cognitive Maps as representations of mentalmodels and group 
beliefs: theoretical and technical issues. In Fuzzy Cognitive maps for Applied Sciences and Engineering From fundamentals to extensions and learning algorithms Ed: Elpiniki I. Papageorgiou. Springer Publishing.

Kosko, B. (1986). Fuzzy cognitive maps. International Journal of Man-Machines Studies, (24), 65-75. 